\title{
Recognition of cigarette brand names and logos by young children in Hong Kong
}

Jean Peters, Carol Lane Betson, Anthony Johnson Hedley, Tai-Hing Lam, Say-Gark Ong, Chit-Ming Wong, Richard Fielding

\begin{abstract}
Objective - To examine the recognition of cigarette brand names and logos by Hong Kong primary school children.
\end{abstract}

Design-Cross-sectional survey with self-completed questionnaires examining smoking behaviour and recognition of 13 food, drink, cigarette, and toothpaste brand names and logos.

Subjects - A total of 9591 primary school children (mean age $=10.3 ; \mathrm{SD}=1.29$ ) living in two districts of Hong Kong included in 1991 as part of a four-year respiratory health, smoking, and air pollution study which started in 1989.

Results-Ever-smoking prevalence was $11 \%(1067) ; 15 \%(759)$ in boys and $7 \%$ (308) in girls, and increased with age. Mean age of smoking the first cigarette was 7.8 years. Brand recognition ranged from $53 \%$ (Salem name) to $95 \%$ (Marlboro name and Salem logo). Significant differences were found by gender and by smoking status for the identification of drink, cigarette, and toothpaste brand groups. After adjustment in a logistic regression model, eversmokers, who were more likely to be boys (adjusted odds ratio $(O R)=2.22 ; 95 \%$ confidence interval $(\mathrm{CI})=1.91$ to 2.57$)$, of older age $(O R=1.54 ; 95 \% C I=1.46$ to 1.62), living in Kwai Tsing district (OR = $1.31 ; 95 \% \mathrm{CI}=1.14$ to 1.50 ), were more successful than never-smokers in identifying cigarette brands $(O R=1.82 ; 95 \%$ $\mathrm{CI}=1.57$ to 2.12 ).

Conclusion-Smoking is a paediatric health problem in Hong Kong; tobacco advertisements are widely recognised by young children and associated with smoking experience. A total ban on environmental advertising is needed as part of a comprehensive policy for the prevention of smoking-related disease in Hong Kong.

(Tobacco Control 1995; 4: 150-155)

Keywords: environmental advertising; brand names, recognition; children

\section{Introduction}

Smoking-related diseases are the most important preventable causes of death in Hong Kong. ${ }^{1}$ In the Asia-Pacific region the ad- vertising and promotion of tobacco to young people in general is intensive, although tobacco companies maintain that their advertising policies and practices are not targeted at the young and that they do not try to influence children to start smoking. ${ }^{2}$ Their stated aims are to persuade adults to change brands or to encourage brand loyalty in those adults who currently smoke. Nevertheless, studies in the US found that specific material from tobacco advertising campaigns was more successfully identified by children than by adults ${ }^{3,4}$ and in some countries the total banning of tobacco advertising is estimated to have resulted in a reduction of tobacco consumption by $4-16 \% 5$

In Hong Kong, only a partial ban on cigarette advertising is in place. Cigarette advertisements are permitted in the print media, are carried by taxis, and large-scale displays, including those running the full height of high-rise buildings, dominate the skyline in urban areas. The high profile that the product receives through this and other means of indirect advertising, such as Salem tennis tournaments, Kent holidays and movies, and Marlboro "Red Hot Hits" (music compact discs) and clothing, projects images of maturity, excitement, glamour, confidence, and success. This has been shown to raise children's awareness of cigarettes, and may encourage them to start smoking. ${ }^{6,7}$ A few studies have been carried out, but none in Asia, to examine the impact of environmental tobacco advertising on primary school children. ${ }^{6,8,9}$

The purpose of this survey was to examine the smoking behaviour of Chinese-speaking primary school children in Hong Kong and their ability to recognise brand names and logos of widely advertised products, including foods, drinks, cigarettes, and toothpaste.

\section{Subjects and methods}

\section{STUDY POPULATION}

In a four-year study started in 1989 to examine respiratory health, smoking, and air pollution, Chinese children in primary classes 3 and 4 and their parents were recruited from 17 schools in two areas of Hong Kong: Southern and Kwai Tsing districts. The original selection of the districts was based on the differences between them in air quality. In 1991 an additional 10 schools, four in Kwai Tsing and six in Southern district, situated 
close to the original schools, were added to the study.

Details of the initial study design, selection of schools and classes in 1989, and any sociodemographic differences between the two districts have been reported elsewhere. ${ }^{10,11}$ The principal criterion for selection of schools in Kwai Tsing was that they were located in a subdistrict with poor air quality, as rated by local officials and the Government Environmental Protection Department. In Southern district, because of its better air quality, all schools were situated in areas of low air pollution. With respect to sociodemographic differences, Kwai Tsing district had more families living in public housing for lower income groups and fewer parents who had continued through to upper secondary or tertiary education.

The data set reported in this paper was taken from the 1991 survey and consisted of the original children in the 1989 survey, now in primary classes 5 and 6 , and the new intake of children in primary classes 3 and 4 from the initial 17 schools, plus children in primary classes 3 and 4 from the schools recruited in 1991.

\section{QUESTIONNAIRES}

In each of the four years of the study, all children and their parents completed questionnaires that covered respiratory health, smoking behaviour, and sociodemographic factors. The ever-smoking experience in the children was found, after adjustment for sociodemographic factors and indoor and outdoor air pollution, to be associated with respiratory health effects including wheeze, nasal symptoms, and sore throat. ${ }^{11}$

The children were asked questions about current smoking status, age of starting to smoke, number of cigarettes smoked in the last 24 hours, sources of cigarettes, and knowledge and attitude related to smoking. In 1991 children were asked to classify six brand names in Chinese characters (Marlboro, Salem, Carlsberg, Martell, Cadbury, and Colgate) and seven colour-reproduced brand logos (Marlboro, Salem, Coca Cola, Carlsberg, McDonald's, Garden bakery and Colgate; figure) of 13 assorted food, drink, cigarette, and toothpaste brands into one of five categories: food, cigarette, drink, other products, or not known. Four of the brands Marlboro, Salem, Carlsberg, and Colgate were presented independently both as a product name and as a product logo.

The completion rate for the 13 brand recognition questions was $99 \%$, with the exception of the McDonald's logo which had a completion rate of $85 \%$. The McDonald's logo gave rise to indecision in the children because it could be categorised in one of three categories-i.e., food, drink, or otherresulting in non-completion of the question in some cases. The questions to the children and the product logos are illustrated in the figure.

The children's questionnaires were administered by a trained research worker and com- pleted in the classroom under supervised conditions. There was no collusion between children and no teachers were present.

\section{ANALYSIS :}

Answers to the brand identification questions were graded 1 for correct and 0 for incorrect. Scores were derived, by summing all the correct answers, for: total brand recognition (maximum score $=13$ ), all brand names (6), all brand logos (7), and each product category: drinks (4), cigarettes (4), food (3), and other (2). In the few instances where there were missing data, the cases were excluded from the analysis.

The child's smoking status was determined from one of six possible answers: (a) have never smoked; (b) tried smoking once or a few times; (c) used to smoke but now do not; (d) smoke sometimes but fewer than one cigarette per week; (e) smoke one to six cigarettes per week; and (f) smoke more than six cigarettes per week. Smoking status was defined as: (1) ever-smoker, from a positive response to answer categories (b)-(f), or (2) never-smoker, from a positive response to category (a).

All analyses were carried out using sPSs $P C+4.0$. Differences between ever-smoking and never-smoking children, in terms of their gender, age, district of residence, and scores of correct answers were analysed by $\chi^{2}$ and $t$ tests, with $95 \%$ confidence intervals (95\% CIs) calculated for all point estimates.

To determine the importance of factors associated with smoking behaviour (eversmokers), the scores for each of the four product categories: food, drink, cigarette, and toothpaste (divided into $100 \%$ correct answers or less than $100 \%$ correct) were included in a logistic regression model together with gender, age (as a continuous variable), and district of residence as independent variables; and from the model, the adjusted odds ratios (ORs) with $95 \%$ CIs were determined for each factor. ${ }^{12}$ The analysis of scores was repeated to examine responses with more than $50 \%$ correct, with responses divided as follows:

- drinks, cigarettes: none, one, or two correct answers compared with three or four correct (ie, 75-100\% correct);

food: none or one correct compared with two or three correct (ie, $67-100 \%$ correct); - other: none or one correct compared with two correct (ie, $100 \%$ correct).

\section{Results}

STUDY POPULATION

In the 1991 survey, 27 schools consisting of 271 primary classes 3-6 took part . A total of 9657 children, representing $99 \%$ of the total child population sampled, completed the questionnaires. The $66(0.7 \%)$ children who failed to indicate their smoking status were excluded from the analysis so the final data set consisted of 9591 children (table 1). Numbers of children in the two districts were similar, with 4917 in Southern district and 4674 in Kwai Tsing. There were no differences be- 
Please indicate what types of product are represented by the following logos or names? (Please tick in the box under the appropriate product $\square$ )

56. Ka Si Park 嘉士伯

57. Man Bo Lo 萬寶路

58. Kut Park Lay 吉百利

59. Go Lo Kit 高露潔

60. Sha Lone 沙龍

61. Ma Dare Lay 馬䇟利

\section{Food Cigarette Drink Others Don't know}

Note: For questions 56-61, the Chinese characters are translated into English according to the Cantonese pronunciation of the characters. The English names are: 56. Carlsberg, 57. Marlboro, 58. Cadbury, 59. Colgate, 60. Salem, 61. Martell.

62.

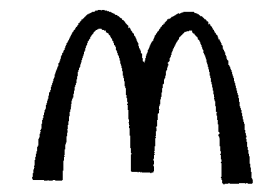

63.

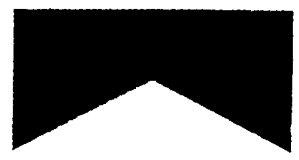

64.

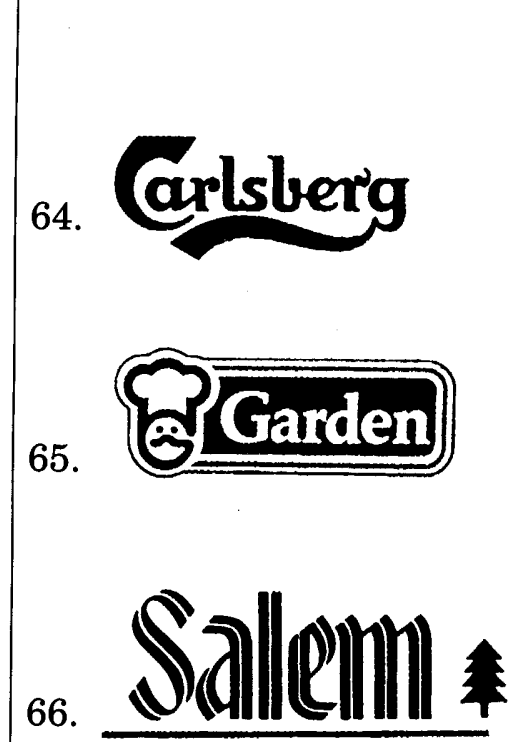

65.
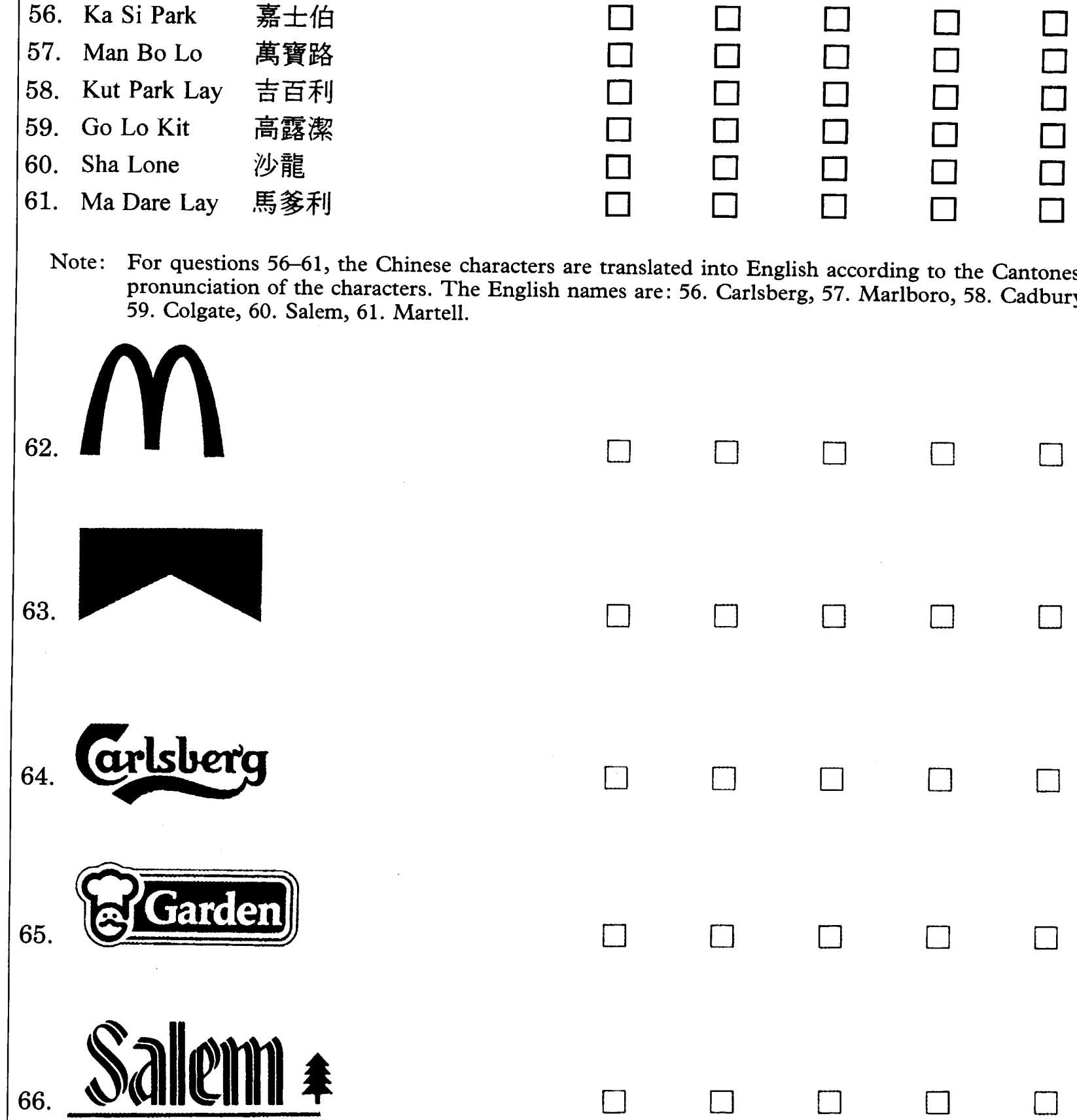

67. Colgate

68.

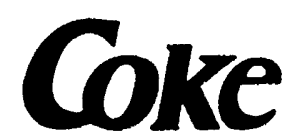


Table 1 Number and prevalence (\%) of children smoking

\begin{tabular}{|c|c|c|c|c|c|}
\hline \multirow[t]{2}{*}{ 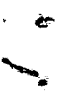 } & \multirow{2}{*}{$\begin{array}{l}\text { Age } \\
\text { (years) }\end{array}$} & \multicolumn{2}{|c|}{ Boys } & \multicolumn{2}{|c|}{ Girls } \\
\hline & & Never-smoker & Ever-smoker & Never-smoker & Ever-smoker \\
\hline $\begin{array}{l}x_{\infty} \\
5 \\
5\end{array}$ & $\begin{aligned} & 8 \\
& 9 \\
& 10 \\
& 11 \\
& 12 \\
& \geqslant \\
& \text { Subtotal }\end{aligned}$ & $\begin{array}{r}753(93) \\
1208(91) \\
981(86) \\
772(79) \\
376(72) \\
73(49) \\
4163(85)\end{array}$ & $\begin{array}{r}59(7) \\
115(9) \\
157(14) \\
204(21) \\
148(28) \\
76(51) \\
759(15)\end{array}$ & $\begin{array}{r}800(97) \\
1340(95) \\
1059(94) \\
728(91) \\
364(87) \\
70(80) \\
4361(93)\end{array}$ & $\begin{array}{c}28(3) \\
71(5) \\
67(6) \\
72(9) \\
52(13) \\
18(20) \\
308(7)\end{array}$ \\
\hline$t$ & Total & \multicolumn{2}{|c|}{4922} & \multicolumn{2}{|c|}{4669} \\
\hline
\end{tabular}

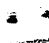

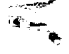$$
-
$$$$
\rightarrow
$$

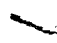$$
=
$$$$
=
$$$$
+
$$$$
-5
$$$$
\rightarrow
$$$$
3
$$

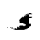

tween districts of residence by gender $\left(\chi^{2}=\right.$ $1.2, \mathrm{df}=1, \mathrm{p}=0.2)$, or by age $(t=1.2, \mathrm{df}=$ 9598, $\mathrm{p}=0.2$ )

\section{SMOKING PREVALENCE}

A total of $1067(11 \%, 95 \% \mathrm{CI}=10.5$ to $11.8 \%$ ) were found to be ever-smokers. Of these, $83 \%(886)$ had tried smoking once or a few times; $8 \%$ (81) used to smoke; $6 \%$ (62) smoked fewer than one cigarette per week, $2 \%$ (24) smoked one to six cigarettes per week, and $1 \%$ (14) smoked more than six cigarettes per week.

There were differences between eversmokers and never-smokers: by district of residence, with $9.8 \% \quad(95 \% \quad \mathrm{CI}=9.0$ to $10.7 \%$ ) ever-smoking children in Southern district and $12.5 \%(95 \% \mathrm{CI}=11.5$ to $13.4 \%)$ in Kwai Tsing $\left(\chi^{2}=17.3, \mathrm{df}=1, \mathrm{p}<0.001\right)$; by gender, with $15.4 \%(95 \% \mathrm{CI}=14.4$ to $16.4 \%$ ) ever-smokers in boys and $6.6 \%(95 \%$ $\mathrm{CI}=5.9$ to $7.3 \%)$ in girls $\left(\chi^{2}=188.8, \mathrm{df}=1\right.$, $\mathrm{p}<0.001)$; by age, with ever-smoking children being older (mean age $=11.1$ years $; 95 \%$ $\mathrm{CI}=11.0$ to 11.2 ) than never-smokers (mean $=10.2 ; 95 \% \mathrm{CI}=10.1$ to 10.4$)(t=20.6, \mathrm{df}$ $=9589, \mathrm{p}<0.001)$.

\section{IDENTIFICATION OF BRANDS}

Successful recognition of the individual brand names and logos was very high overall with an average of $82 \%$, ranging from $53 \%$ (Salem name) to $95 \%$ (Marlboro name and Salem logo). Of the three most successfully identified brands, the top two were tobacco products: Marlboro name (95\%) and Salem logo (95\%), and the third was a food, Garden bakery $(94 \%)$

There were no significant differences in mean total scores for the 13 items between districts but there were gender differences with mean scores of $11.0(95 \% \mathrm{CI}=10.9$ to $11.1)$ and $10.6(95 \% \mathrm{CI}=10.5$ to 10.6$)$ for boys and girls, respectively $(t=9.3, \mathrm{df}=8817$, $\mathrm{p}<0.001)$. More boys correctly identified three of the four cigarette brand names or logos, two of the three alcoholic drinks, and the Colgate logo, whereas girls were more successful only in the recognition of the Garden bakery logo (table 2).

Recognition of products was greater with increasing age; successful identification of all 13 items occurred in $10 \%$ (153) of eight-yearolds but $32 \%(71)$ of 13 -year-olds $\left(\chi^{2}=360.9\right.$, $\mathrm{df}=1, \mathrm{p}<0.001)$. However, even in the eight-
Table 2 Boys and girls with 100\% correct answers

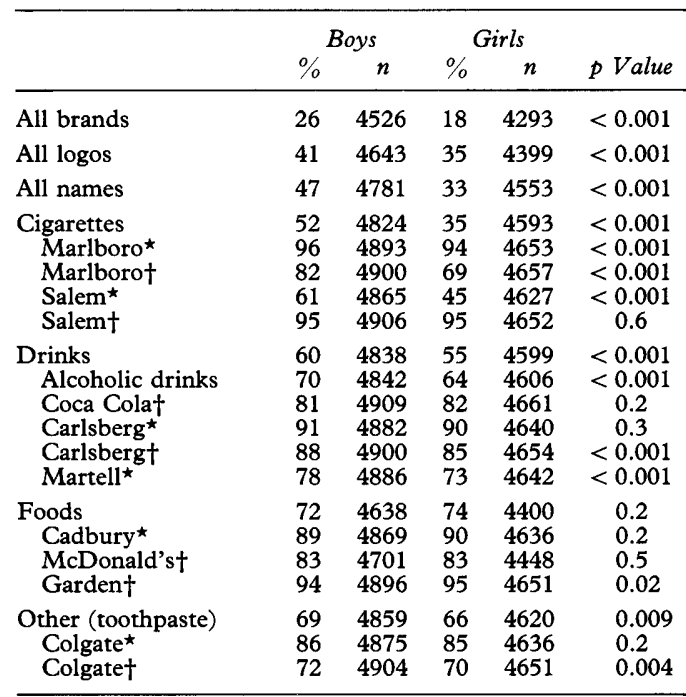

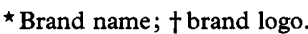

year-old age group, $1163(72 \% ; 95 \% \mathrm{CI}=60$ to $84 \%$ ) of the children identified three or more of the cigarette names and logos correctly.

\section{IDENTIFICATION OF BRANDS BY SMOKING} BEHAVIOUR

Overall there were significant differences between never-smokers and ever-smokers in mean total scores $(t=6.5, \mathrm{df}=8817, \mathrm{p}<$ $0.001)$ with ever-smokers scoring higher (11.2; $95 \% \mathrm{CI}=11.1$ to 11.3 ) than never-smokers $(10.7 ; 95 \% \mathrm{CI}=10.7$ to 10.8$)$. For the four categories of products, the biggest differences between ever-smokers and never-smokers were seen in the cigarette category $(\mathrm{OR}=$ $2.39 ; 95 \% \mathrm{CI}=2.10$ to 2.72 ). Other significant differences occurred for drinks (OR = $1.29 ; 95 \% \mathrm{CI}=1.13$ to 1.47$)$ and toothpaste $(\mathrm{OR}=1.23 ; 95 \% \mathrm{CI}=1.07$ to 1.41$)$ (table 3$)$.

With respect to recognition of individual items, there were significant differences (unadjusted OR) with ever-smokers being more successful for all four cigarette items and the Martell name (table 3). In only one instance, for Garden bakery, were neversmokers significantly more successful than ever-smokers.

In the cigarette category, $756(72 \%$; $95 \%$ $\mathrm{CI}=69$ to $75 \%$ ） ever-smokers correctly identified both brand names compared with $4181(50 \% ; 95 \% \mathrm{CI}=49$ to $51 \%)$ neversmokers, whereas $871(82 \% ; 95 \% \mathrm{CI}=80$ to $85 \%)$ and $6117(72 \% ; 95 \% \mathrm{CI}=71$ to $73 \%)$ ever-smokers and never-smokers, respectively, correctly identified both cigarette logos.

After adjustment for age, gender, and district of residence, cigarette brand identification was strongly associated with ever-smoking. This was the result of two comparisons: one in which recognition of both cigarette brands was $100 \%$ correct compared with responses < $100 \%$ correct; and another in which those with more than $50 \%$ answers correct were compared with those with fewer answers correct (table 4). In contrast, the associations 
Table 3 Never-smokers and ever-smokers with 100\% correct answers

\begin{tabular}{|c|c|c|c|c|c|}
\hline & \multicolumn{2}{|c|}{$\begin{array}{l}\text { Never- } \\
\text { smokers }\end{array}$} & \multicolumn{2}{|c|}{$\begin{array}{c}\text { Ever- } \\
\text { smokers }\end{array}$} & \multirow{2}{*}{$\begin{array}{c}\text { Unadjusted } \\
\text { OR }(95 \% C I)\end{array}$} \\
\hline & $n$ & $\%$ & $n$ & $\%$ & \\
\hline All brands & 7827 & 19 & 992 & 30 & $1.77(1.54-2.04)$ \\
\hline All logos & 8020 & 35 & 1022 & 41 & $1.29(1.13-1.47)$ \\
\hline All names & 8300 & 37 & 1034 & 55 & $2.13(1.87-2.42)$ \\
\hline $\begin{array}{l}\text { Cigarettes } \\
\text { Marlboro } \\
\text { Marlboro† } \\
\text { Salem }^{\star} \\
\text { Salem } \dagger\end{array}$ & $\begin{array}{l}8376 \\
8487 \\
8500 \\
8441 \\
8494\end{array}$ & $\begin{array}{l}41 \\
95 \\
75 \\
50 \\
95\end{array}$ & $\begin{array}{l}1041 \\
1059 \\
1057 \\
1051 \\
1064\end{array}$ & $\begin{array}{l}62 \\
97 \\
84 \\
73 \\
96\end{array}$ & $\begin{array}{l}2.39(2.10-2.72) \\
1.63(1.13-2.33) \\
1.81(1.52-2.15) \\
2.60(2.26-3.00) \\
1.40(1.01-1.93)\end{array}$ \\
\hline $\begin{array}{l}\text { Drinks } \\
\text { Alcoholic drinks } \\
\text { Coca Cola } \dagger \\
\text { Carlsberg } \\
\text { Carlsberg } \dagger \\
\text { Martell }^{\star}\end{array}$ & $\begin{array}{l}8392 \\
8403 \\
8505 \\
8470 \\
8491 \\
8471\end{array}$ & $\begin{array}{l}56 \\
65 \\
81 \\
90 \\
86 \\
75\end{array}$ & $\begin{array}{l}1045 \\
1045 \\
1065 \\
1052 \\
1063 \\
1057\end{array}$ & $\begin{array}{l}62 \\
73 \\
80 \\
91 \\
88 \\
82\end{array}$ & $\begin{array}{l}1.29(1.13-1.47) \\
1.40(1.21-1.61) \\
0.94(0.80-1.10) \\
1.16(0.92-1.45) \\
1.17(0.97-1.42) \\
1.51(1.28-1.78)\end{array}$ \\
\hline $\begin{array}{l}\text { Foods } \\
\text { Cadbury* } \\
\text { McDonald's } † \\
\text { Garden } \dagger\end{array}$ & $\begin{array}{l}8017 \\
8448 \\
8118 \\
8483\end{array}$ & & $\begin{array}{l}1021 \\
1057 \\
1031 \\
1064\end{array}$ & $\begin{array}{l}69 \\
89 \\
83 \\
93\end{array}$ & $\begin{array}{l}1.00(0.87-1.14) \\
0.93(0.75-1.14) \\
0.97(0.82-1.15) \\
0.76(0.59-0.97)\end{array}$ \\
\hline $\begin{array}{l}\text { Other (toothpaste) } \\
\text { Colgate } \\
\text { Colgate }\end{array}$ & $\begin{array}{l}8424 \\
8454 \\
8492\end{array}$ & & $\begin{array}{l}1055 \\
1057 \\
1063\end{array}$ & $\begin{array}{l}70 \\
88 \\
73\end{array}$ & $\begin{array}{l}1.23(1.07-1.41) \\
1.21(1.00-1.46) \\
1.14(0.99-1.32)\end{array}$ \\
\hline
\end{tabular}

* Brand name; † brand logo.

$\mathrm{OR}=$ odds ratio; $\mathrm{CI}=$ confidence interval.

Table 4 Demographic characteristics and correct identification of brands as predictors of ever-smoking children

\begin{tabular}{lcc}
\hline & \multicolumn{2}{c}{ Adjusted OR $(95 \%$ CI $)$} \\
\cline { 2 - 3 } Category & $\begin{array}{c}100 \% \text { correct for } \\
\text { all brands }\end{array}$ & $\begin{array}{c}>0 \% \text { correct for } \\
\text { all brands }\end{array}$ \\
\hline Gender (male) & $2.22(1.91-2.57)$ & $2.29(1.98-2.66)$ \\
District (Kwai Tsing) & $1.31(1.14-1.50)$ & $1.29(1.12-1.48)$ \\
Age (per year) & $1.54(1.46-1.62)$ & $1.58(1.50-1.67)$ \\
Cigarettes & $1.82(1.57-2.12)$ & $1.82(1.44-2.30)$ \\
Drinks & $1.04(0.89-1.21)$ & $0.92(0.74-1.14)$ \\
Food & $0.82(0.70-0.96)$ & $0.72(0.51-1.03)$ \\
Toothpaste & $0.82(0.70-0.97)$ & $0.89(0.76-1.05)$ \\
\hline
\end{tabular}

$\mathrm{OR}=$ odds ratio $; \mathrm{CI}=$ confidence interval.

between smoking and other categories were weak and likely to be chance findings. Eversmokers tended to be older boys in Kwai Tsing district. The logistic model correctly predicted $89 \%$ of all cases as ever-smokers or neversmokers.

\section{Discussion}

In Hong Kong, prevalence rates for experimental smoking among secondary school children are high, ranging from $20-47 \%$ in $13-16$-year-olds ${ }^{13}$ and $8-57 \%$ in $11-21$-yearolds. ${ }^{14}$ In 1989 , we were the first to report an ever-smoking prevalence of $8 \%$ in primary classes 3 and 4, consisting mostly of children aged 8-10 years. ${ }^{15}$

In 1982 Chapman and Fitzgerald ${ }^{16}$ found a twofold difference in identification of edited cigarette advertisements by smokers compared with non-smoking Australian children and the debate continues about the impact of advertising on all age groups in society. ${ }^{5,17}$ Young people in Hong Kong show differences in smoking behaviour compared with their Western counterparts in that smoking prevalence, especially for girls, is lower at a given age. ${ }^{13,14,18}$ Their successful recognition of advertised tobacco brands, however, especially by ever-smokers, shows that the level of awareness is similar to that found in other studies in the West. ${ }^{3,8,9}$ Tobacco advertising and tobacco products are clearly making an impression on young children. Even though recognition levels were higher in smoking children, awareness of the product and its promotional messages may influence nonsmoking children as young as seven years of age.

Other authors, working in an entirely separate cultural environment, have demonstrated the impact of product promotions on very young children. A recent study in the US reported recognition rates among 3-6-yearolds, for Coca Cola and McDonald's, similar to those reported here. ${ }^{9}$ One would expect young children to be able to identify such products because they use them. In primary school children, however, high awareness of the Salem logo and Marlboro name (the two brands identified most successfully in this study from all of those given) is likely to be due to the style and content of advertising and its appeal to young people. In Hong Kong at present, many taxi doors are emblazoned with Joe Camel, a cartoon character recognisable in the US by $91 \%$ of six-year-olds. ${ }^{9}$ This runs directly counter to clause 9 of the proposed Charter of Children's Rights to freedom from tobacco advertising. ${ }^{19}$

Advertising bans are effective in reducing tobacco consumption ${ }^{5}$ and there is considerable local support for strong measures against tobacco advertising in Hong Kong. A 1988 study found that $75 \%$ of Hong Kong adults favoured and only $20 \%$ opposed restrictions on tobacco advertisements in newspapers and magazines, whereas $76 \%$ favoured and $19 \%$ opposed restrictions in public transport. ${ }^{20} \mathrm{~A}$ similar but more recent study found that $53 \%$ of local residents favoured, and $29 \%$ opposed, a total ban on tobacco advertising, including advertisements in printed publications and on billboards. $^{21}$

What is now needed in Hong Kong is legislative action to support both this majority opinion and the Territory's declared health policy, which is to prevent smoking-related diseases. Hong Kong currently imposes some restrictions on cigarette advertisements such as banning them on radio and television and in cinemas. Children are still continuously exposed to indirect advertisements in these media, however, as well as direct advertisements in printed publications and displays, sources from which other reports have demonstrated that they can successfully recall the names and logos of the products advertised. ${ }^{22}$ The data presented here indicate that partial restrictions on advertisements - for example, limitation to the use of the name and picture of the product and a health warning - will not protect children from the overall effect of environmental tobacco advertising. The World Health Organisation's Regional Office for the Western Pacific, in its Action Plan on Tobacco or Health for $1995-1999,{ }^{23}$ has called for a "Tobacco-advertising free region by the year 2000 " and the Hong Kong Government has endorsed the plan. 
This study is the first of its kind in Asia and indicates that new smoking prevention policies to protect young people are needed now, if we are to prevent their recruitment to the ranks of smokers, and if there is any intention to reduce future smoking-related health problems and demands on health resources.

The authors wish to thank the Environmental Protection Department, Hong Kong Government, the Hong Kong Jockey Club (Charities) Limited, Kwai Tsing District Board, and Glaxo Hong Kong Limited for support to the Respiratory Health Study, the Mary Sun Medical Scholarship Fund for support to CM Wong, and all the schools, teachers, children, and their parents for their cooperation and participation in this study.

1 Department of Health. Public health report no 1. Coronary heart disease and lung cancer. Hong Kong: Department of Health, 1994.

2 Raftery J. Advertising and smoking. A smouldering debate. $\mathrm{Br} \mathcal{F}$ Addict $1989 ; 84$ : $1241-6$.

3 DiFranza JR, Richards JW, Paulman PM, et al. Nabisco's cartoon camel promotes Camel cigarettes to children. F $A M A$ 1991; 266: 3149-53.

4 Pierce JP, Gilpin E, Burns DM, et al. Does tobacco advertising target young people to start smoking? $\mathscr{f} A M A$ $1991 ; 266: 3154-8$

5 Smee $C$. Effect of tobacco advertising on tobacco consumption. $A$ discussion document reviewing the evidence. London: Economics and Operation

6 Charlton A. Children's advertisement awareness related to their views on smoking. Health Educ f 1986; 45: 75-8.

7 Potts $H$, Gillies $P$, Herbert $M$. Adolescent smoking and opinion of cigarette advertisements. Health Educ Res 1986; 1 : 195-201.

$-3$

8 Aitken P, Leathar D, O'Hagan F, Squair S. Children's awareness of cigarette advertisements and brand imagery. Br 7 Addict 1987; 82: 615-22.

9 Fischer P, Schwartz MP, Richards JW, Goldstein AO Rojas TH. Brand logo recognition by children aged 3 to 6 years $\mathcal{Y} A M A 1991 ; 266$ : 3145-8.
10 Ong SG, Liu J, Wong CM, et al. Studies on the respiratory health of primary school children in urban communities in Hong Kong. Sci Total Environ 1991; 106: 121-35.

11 Department of Community Medicine. Air pollution and respiratory health in primary school children, 1989-1992. Report to the Environmental Protection Department, Hong Koport to the Environmental Protection Department, Hong munity Medicine, University of Hong Kong, 1993 (333 munity

12 Fleiss JL. Statistical methods for rates and proportions, 2nd ed. New York: Wiley, 1981: 75.

13 Hertz AZ. Smoking among junior secondary school children in Hong Kong in 1990. A report to The Hong Kong Council on Smoking and Health. Hong Kong: Council on Smoking and Health, 1990: 7 .

14 Narcotics Division 1992 Survey on drug use among students of secondary schools and technical institutes in Hong Kong. Hong Kong: Government Secretariat, 1993.

15 Department of Community Medicine. Studies on respiratory health in Hong Kong. Report No 2. Department of Community Medicine, University of Hong Kong, 1991 : 19.

16 Chapman S, Fitzgerald B. Brand preference and advertising recall in adolescent smokers: some implications for health promotion. Am f Publ Health 1982; 72: 491-4.

17 Waxman RH. Tobacco marketing profiteering from children. $\mathcal{F} A M A 1991 ; 266$ : 3185-6.

18 Faculty of Public Health Medicine. Children and smoking. Guidelines for health promotion no 33. London: Roya College of Physicians of the UK, 1993.

19 Proboscis. Children's right to freedom from tobacco-a charter. London: The Health Summary, 32 King Henry's charter. London: The

20 Lam TH, Donnan SPB, Cheng KK, Chan NF. A public opinion survey on proposed legislative changes on smoking control. In: Durston B, Jamrozik K, eds Tobacco and Health 1990. The Global War. Perth: Organising Committee of the Seventh World Conference on Tobacco and Health, 1990: 726-8.

21 Cheng KK, Hedley AJ, Lam TH, Peters J, Bacon-Shone J, Chan A. A public opinion survey on measures related to the control of smoking in Hong Kong. A report to The Hong Kong Council on Smoking and Health. Hong Kong. Council on Smoking and Health, 1993: 6 .

22 Nelson E, Charlton A Children and advertising. does the voluntary agreement work? Health Educ 7 1991; 50: $12-15$.

23 World Health Organisation Action Plan on Tobacco or Health for 1995-1999. Manila: World Health Organisation Regional Office for the Western Pacific, 1994; 1.

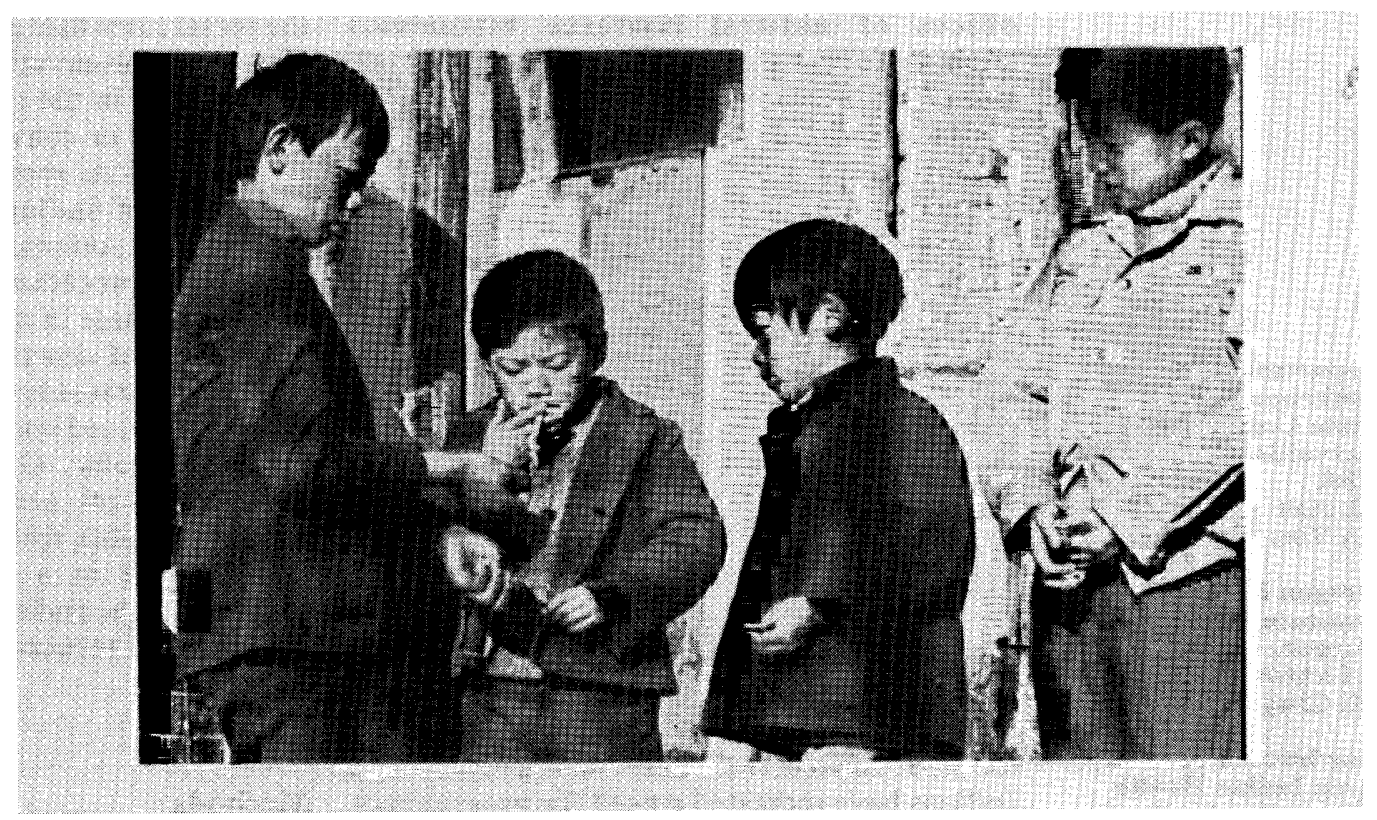

Children smoking, China. Source: Wang Gang-Feng/Panas Pictures. 